\title{
High quantitative and no molecular differentiation of a freshwater snail (Galba truncatula) between temporary and permanent water habitats
}

\author{
ELODIE CHAPUIS, SANDRINE TROUVE, BENOIT FACON, LOÏC DEGEN and JEROME GOUDET \\ Department of Ecology and Evolution, Biophore, UNIL-Sorge, University of Lausanne, CH-1015 Lausanne, Switzerland
}

\begin{abstract}
We investigate the variation in quantitative and molecular traits in the freshwater snail Galba truncatula, from permanent and temporary water habitats. Using a common garden experiment, we measured 20 quantitative traits and molecular variation using seven microsatellites in 17 populations belonging to these two habitats. We estimated trait means in each habitat. We also estimated the distributions of overall genetic quantitative variation $\left(Q_{\mathrm{ST}}\right)$, and of molecular variation $\left(F_{\mathrm{ST}}\right)$, within and between habitats. Overall, we observed a lack of association between molecular and quantitative variance. Among habitats, we found $Q_{\mathrm{ST}}>F_{\mathrm{ST}}$, an indication of selection for different optima. Individuals from temporary water habitat matured older, at a larger size and were less fecund than individuals from permanent water habitat. We discuss these findings in the light of several theories for life-history traits evolution.
\end{abstract}

Keywords: Galba truncatula, life history strategy, local adaptation, population differentiation, $Q_{\mathrm{ST}}-F_{\mathrm{ST}}$ comparison, quantitative traits

Received 17 December 2006; revision accepted 13 April 2007

\section{Introduction}

Understanding how genetic variation is maintained in natural populations is a central issue in evolutionary biology (Barton \& Turelli 1989; Reed \& Frankham 2001; Lenormand 2002; Hedrick 2006). Four forces - mutation, drift, migration, and selection - can generate changes in the level of genetic variation within and among populations (Hartl \& Clark 1997). There is a long-standing history of models predicting the change in gene frequencies under nonselective forces (e.g. Wright 1951; Kimura 1983) and the effects of these forces have been frequently documented in natural populations (e.g. Wright 1978; Slatkin 1985). However, natural selection remains the major force driving adaptation and evolutionary changes, especially in the context of heterogeneous environments (e.g. Levene 1953; Gillespie \& Turelli 1989; Byers 2005). Populations living in different environments can evolve different life history strategies (for a review see Reznick et al. 2002). Early studies were interested in how environments that differ in their level of stability select for different life

Correspondence: Jérôme Goudet, Fax: +41 21692 4265;

E-mail: jerome.goudet@unil.ch history strategies: McArthur \& Wilson (1967) showed that in a variable environment that may cause fluctuation in density-independent mortality, individuals should reproduce early, have a small body size and a large clutch size in order to ensure reproduction. In contrast, late reproduction, large body size and small clutch size should be selected for a stable environment. However, this vision has been deemed too simple (Stearns 1976, 1977), and new developments focused on species specific features, in particular their ecology. For instance, Grime (1977) suggested that plants could be classified according to three life history strategies determined by the level of stress and disturbance present in the environment, and Dillon (2000) suggested that freshwater molluscs could also be classified according to three different life history strategies.

There is local adaptation to an environment when native organisms have a higher fitness than non-native ones coming from different environments (William 1966). One way to test for local adaptation is to perform reciprocal transplants of individuals in wild populations (for review see Kawecki \& Ebert 2004), but this is not always feasible in natural populations. An alternative method to test for local adaptation, suggested by Spitze (1993), is to analyse the distribution of molecular and quantitative variation 
among populations in a common environment. The comparison of molecular $\left(F_{\mathrm{ST}} \&\right.$ Wright 1952) and quantitative $\left(Q_{\mathrm{ST}} \&\right.$ Spitze 1993) differentiation of populations can provide information on the relative effect of selection and drift in shaping this differentiation, in particular for populations from contrasted environments. For a neutral additive trait at migration-drift equilibrium, theory predicts that $Q_{\mathrm{ST}}=F_{\mathrm{ST}}$ (Whitlock 1999). If $Q_{\mathrm{ST}}>F_{\mathrm{ST}}$, directional selection is thought to be acting by favouring different phenotypes (and thus genotypes) in different populations (Merilä \& Crnokrak 2001; McKay \& Latta 2002). $Q_{\mathrm{ST}}<F_{\mathrm{ST}}$ reflects the action of homogeneous stabilizing selection leading to similar phenotypes in different populations. Studies comparing $Q_{\mathrm{ST}}$ and $F_{\mathrm{ST}}$ in different environments have often investigated populations along a latitudinal (e.g. Lynch et al. 1999; Storz 2002; Palo et al. 2003; Stenøien et al. 2005) or a climatic gradient (McKay et al. 2001), and have typically found that $Q_{\mathrm{ST}}>F_{\mathrm{ST}}$, thus providing evidence for spatially varying selection across these gradients. But in these studies, populations that differ in their ecological settings were also distant geographically, and could thus differ for other reasons than the ecological factor invoked (Volis et al. 2005). Only a limited number of recent studies compared two contrasted types of habitat in adjacent locations, thus excluding confounding geographical effects (Steinger et al. 2002; Saint-Laurent et al. 2003; GomezMestre \& Tejedo 2004).

Freshwater species, in particular molluscs, offer the opportunity for such studies. They are commonly found in either temporary or permanent water habitats, often in the same geographical area, and the life history strategies of individuals of the same species living in these distinct environments can differ markedly (examples for freshwater snails are reviewed in Dillon 2000). For instance, Brown (1985) transferred juvenile snails between permanent water and temporary water ponds and found that snails from the temporary water habitat reproduced earlier and at a smaller size in both habitats.

The mainly selfing freshwater gastropod Galba truncatula can be found in both permanent (e.g. streams or ponds that do not dry out) and temporary water habitats (pools or wet meadows that freeze during winter and dry during summer) within the same locality. Trouvé et al. $(2003,2005)$ have previously shown that genetic drift is certainly acting in $G$. truncatula, as effective sizes were found to be extremely small. As strong genetic drift is known to counteract the efficacy of selection (Frankham 1999), demonstrating the action of selection in this species would provide a strong evidence for the power of natural selection to overcome even the strongest drift.

We studied G. truncatula populations from permanent and temporary water habitats at a local scale (a few kilometres) where the two types of habitat are intermingled. Using a common garden experiment, we measured 20 quantitative traits at different life stages, including measures of fecundity, in individuals from populations of each habitat. We also estimated population and habitat differentiation at neutral markers using microsatellites. Using a large number of populations and traits measured in a common environment, we used the $Q_{\mathrm{ST}}-F_{\mathrm{ST}}$ comparison to test for the occurrence of local adaptation between habitats. Since these habitats are strongly contrasted, and other snail species from these habitats have been found to differ markedly in their life history (e.g. Brown 1985), we expect selection to overcome the action of drift and favour different life history strategies in the two habitats. Thus, we predict that $Q_{\mathrm{ST}}>F_{\mathrm{ST}}$ between habitats. Under the theory put forward by McArthur \& Wilson (1967), we would expect individuals from temporary water habitats to reach sexual maturity earlier, at a smaller size and to be more fecund than individuals from permanent water habitats. However, Dillon (2000) has suggested that snails from temporary water habitats might be adapted to drought stress and thus mature later and have a lower fecundity than snails from permanent water habitats. Our experimental data will be used to test which of these two theories better fits the life history strategies developed by G. truncatula.

\section{Materials and methods}

\section{Biological and ecological frameworks}

The freshwater snail Galba truncatula, an intermediate host of the liver fluke (Fasciola hepatica), has been mainly studied in the laboratory. It reproduces nearly exclusively by selffertilization, with a selfing rate above $90 \%$ (Trouvé et al. $2003,2005)$. It lays eggs in places of high humidity such as moist mud (Kendall 1953). Two periods of egg laying, one in spring and one in autumn, have been recorded in the laboratory and in the wild (Morel-Vareille 1973; Fretter \& Peake 1975). As mentioned above, G. truncatula inhabits both permanent and temporary water habitats that do not seem to differ in other characteristics (e.g. parasite prevalence, E. Chapuis and J. Goudet unpublished). Since G. truncatula is a nonoperculate pulmonate snail, its aperture cannot be closed to prevent water loss. Therefore, drought stress may be an important ecological factor that differs between these two habitats. However, adults have been reported to survive drought conditions for several weeks and even months (Peters 1938; Kendall 1949). Several factors have been suggested to explain this resistance. In natural conditions, snails may adhere their aperture to the soil surface (thus reducing dehydration), or bury into deeper ground where humidity is conserved (Kendal 1949). Thus, a population from a temporary water habitat is not necessarily a demographically unstable population, because individuals may survive long periods of drought. This is confirmed by previous estimates of 


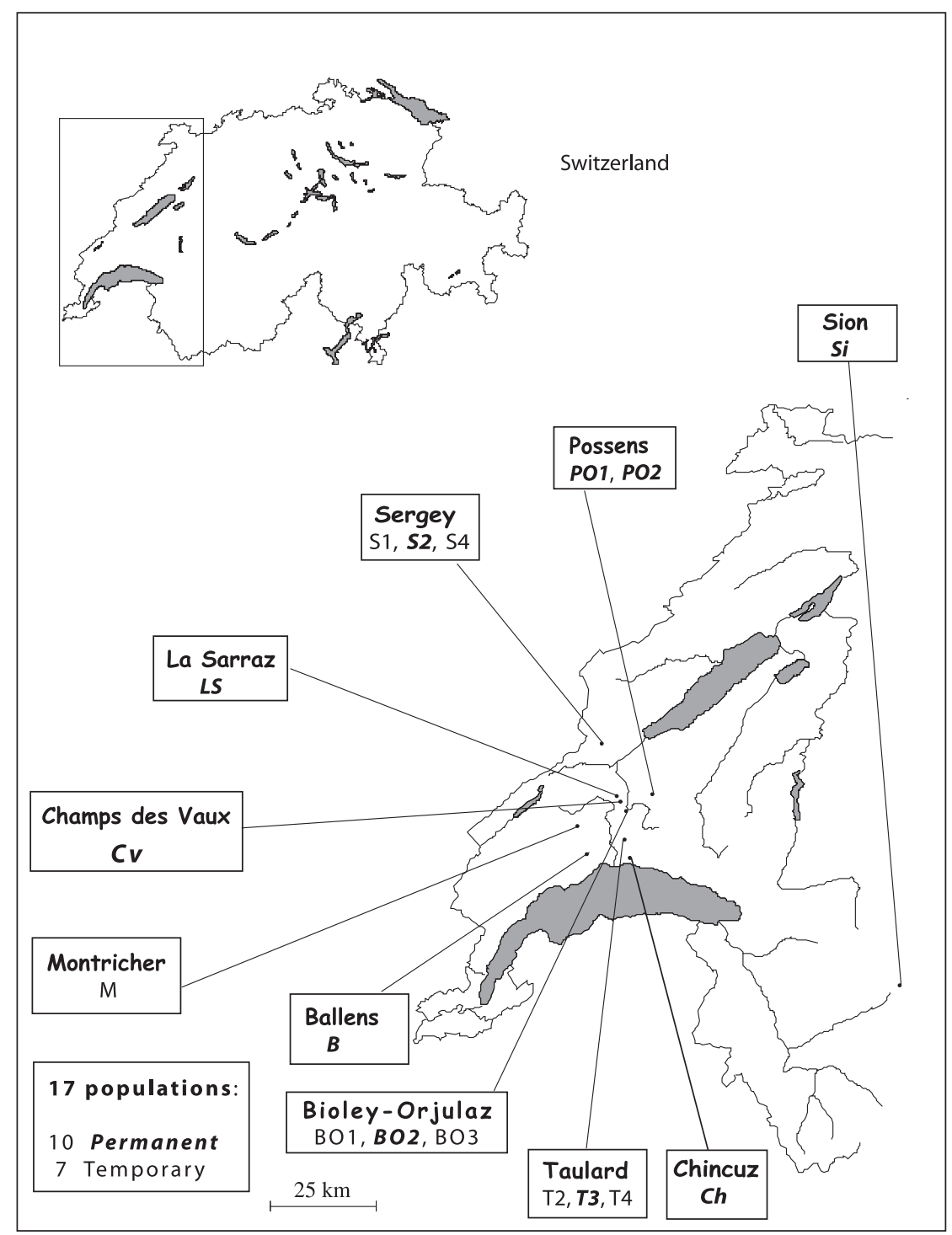

Fig. 1 Sampling locations of the 17 populations studied. Populations from permanent water habitat are represented in bold italics and those from temporary water habitat in normal font. The two habitat types can co-occur in the same locality.

effective population size in temporary and permanent water populations (Trouvé et al. 2005), which are not significantly different, an indication that extinctions are not more common in one habitat type than the other.

\section{Sampling and experimental design}

In June 2003, a total of 17 Galba truncatula populations were sampled in 10 localities in western Switzerland (Fig. 1). Temporary and permanent water habitats are commonly colonized by freshwater molluscs and are typically characterized using the permanency of water within populations over time (see Henry 2002; Bousset et al. 2004; Henry et al. 2005). We visited the sites during spring and summer 2003 and in autumn 2004 to classify populations in temporary or permanent water habitats, as in Trouvé et al. $(2003,2005)$. If the sites were found to be dry at least once during the three to four visits, they were considered as temporary water, otherwise they were considered as permanent water. The 17 populations are described in Table 1 . The occurrence of a dry period could be linked to the size and depth of the site, but signs of human activity, such as a nearby quarry, could explain why small water pools can remain in water throughout the year (the LS population for instance, see Fig. 1). Note that populations from both temporary water and permanent water habitats within the same locality (Fig. 1) can be strongly genetically differentiated despite their proximity (Trouvé et al. 2003, 2005). Ten populations were sampled in permanent water habitats and seven in temporary water ones. The random geographical distribution of habitat types was tested using a Mantel-test carried out between the matrices of geographical distance and habitat similarity between populations with the software FSTAT 2.9.4 (Goudet 1995). 
Table 1 Population characteristics including the site description, the approximate area of the site, the maximal depth, the presence and nature of human activity, the number of visits from spring 2003 to autumn 2004 and the number of drought events. These characteristics allow us to determine the habitat type of the populations, i.e. permanent water $(\mathrm{P})$ or temporary water $(\mathrm{T})$

\begin{tabular}{|c|c|c|c|c|c|c|c|}
\hline Pop & Site type & Size & Depth & Human activity & Number of visits & Number of drought & Habitat \\
\hline B & Puddle & $1 \times 1 \mathrm{~m}$ & $<50 \mathrm{~cm}$ & Gravel pit & 4 & 0 & $\mathrm{P}$ \\
\hline BO1 & Puddle & $20 \times 10 \mathrm{~cm}$ & $<5 \mathrm{~m}$ & Gravel pit & 4 & 1 & $\mathrm{~T}$ \\
\hline $\mathrm{BO} 2$ & Pond & $20 \times 15 \mathrm{~m}$ & $<3 \mathrm{~m}$ & Gravel pit & 4 & 0 & $\mathrm{P}$ \\
\hline BO3 & Puddle & $1 \times 15 \mathrm{~cm}$ & $<5 \mathrm{~cm}$ & Gravel pit & 3 & 2 & $\mathrm{~T}$ \\
\hline $\mathrm{Ch}$ & Stream & $1 \mathrm{~m}$ & $<50 \mathrm{~cm}$ & Field & 3 & 0 & $\mathrm{P}$ \\
\hline $\mathrm{Cv}$ & Pond & $6 \times 3 \mathrm{~m}$ & $<3 \mathrm{~m}$ & No & 3 & 0 & $\mathrm{P}$ \\
\hline LS & Puddle & $30 \times 15 \mathrm{~cm}$ & $<5 \mathrm{~cm}$ & Gravel pit & 4 & 0 & $\mathrm{P}$ \\
\hline M & Puddle & $10 \times 10 \mathrm{~cm}$ & $<5 \mathrm{~cm}$ & Field & 3 & 2 & $\mathrm{~T}$ \\
\hline PO1 & Pond & $15 \times 60 \mathrm{~m}$ & $<3 \mathrm{~m}$ & Tile works & 3 & 0 & $\mathrm{P}$ \\
\hline $\mathrm{PO} 2$ & Pond & $15 \times 60 \mathrm{~m}$ & $<3 \mathrm{~m}$ & Tile works & 3 & 0 & $\mathrm{P}$ \\
\hline S1 & Puddle & $2 \times 1 \mathrm{~m}$ & $<5 \mathrm{~cm}$ & Field & 3 & 1 & $\mathrm{~T}$ \\
\hline S2 & Reed bed & $15 \times 10 \mathrm{~m}$ & $<5 \mathrm{~cm}$ & Gravel pit & 3 & 0 & $\mathrm{P}$ \\
\hline S4 & Stream & $1.5 \mathrm{~m}$ & $<50 \mathrm{~cm}$ & Gravel pit & 3 & 2 & $\mathrm{~T}$ \\
\hline $\mathrm{Si}$ & River & $5 \mathrm{~m}$ & $<50 \mathrm{~cm}$ & No & 1 & 0 & $\mathrm{P}$ \\
\hline $\mathrm{T} 2$ & Puddle & $30 \times 20 \mathrm{~cm}$ & $<5 \mathrm{~cm}$ & Gravel pit & 4 & 3 & $\mathrm{~T}$ \\
\hline $\mathrm{T} 3$ & Reed bed & $10 \times 5 \mathrm{~m}$ & $<5 \mathrm{~cm}$ & Gravel pit & 4 & 0 & $\mathrm{P}$ \\
\hline $\mathrm{T} 4$ & Stream & $1 \mathrm{~m}$ & $<5 \mathrm{~cm}$ & Gravel pit & 4 & 2 & $\mathrm{~T}$ \\
\hline
\end{tabular}

No correlation was found between habitat type and geographical distance $\left(R^{2}=0.45, P=0.43\right)$.

From 30 to 90 individuals were collected in each population and brought back to the laboratory (generation $0, \mathrm{G}_{0}$ ). They were kept isolated in Petri dishes $(5 \mathrm{~cm}$ diameter) filled with lake water and fed with cereal flour specifically for snail breeding (TEXTIER). The photoperiod was set to $12 \mathrm{~h}$ of light then $12 \mathrm{~h}$ of dark, and room temperature was maintained at $19 \pm 1^{\circ} \mathrm{C}$. Water was changed every 10 days, and the Petri dishes were moved at random to avoid any spatial effect within the rearing room. Egg capsules from $G_{0}$ individuals were collected in order to constitute $G_{1}$ families. All individuals of the collected capsule were kept together until the 19th day after hatching. On the 20th day, three to five randomly chosen $G_{1}$ individuals from each family (depending on clutch size) were isolated until the end of the experiment. Thus, $\mathrm{G}_{1}$ snails reproduced by selfing, the predominant mating system of this species (Trouvé et al. 2003). Ten families were retained for each population and three $G_{1}$ individuals were measured per family, on average. The experimental design is illustrated in Fig. 2.

\section{Molecular markers}

Between 16 and $50 \mathrm{G}_{0}$ individuals per population were genotyped at seven microsatellite loci (loci 9, 16, 20, 21, 29, 36 and 37) following the procedure described in Trouvé et al. (2000).

Expected heterozygosity (following Nei 1987) $\left(H_{\mathrm{E}}\right)$, and allelic richness $\left(R_{\mathrm{S}}\right)$ was estimated for each locus and for each population using the software FSTAT version 2.9.4 (Goudet 1995). The selfing rate (s) of each population was estimated using $F_{\mathrm{IS}}$ as $s=2 F_{\mathrm{IS}} /\left(1+F_{\mathrm{IS}}\right)$ (Hartl \& Clark 1997). Selfing rate estimated via $F_{\mathrm{IS}}$ was found to give essentially the same results as previous estimates based on progeny array analyses (Trouvé et al. 2003).

Population structure was analysed using hierarchical $F$-statistics, estimated from variance components of gene frequencies (Weir \& Cockerham 1984; Weir 1996; Yang 1998) with the package HIERFSTAT (Goudet 2005) for the statistical software R (R Development Core Team 2004). The following notation was used: Hab stands for habitat, Pop refers to population and Total to total. Accordingly, $F_{\text {HabTotal }}$ is the correlation of genes within habitats relative to the total and is estimated as $\sigma_{\mathrm{Hab}}^{2} /\left(\sigma_{\mathrm{Hab}}^{2}+\sigma_{\mathrm{Pop}}^{2}+\sigma_{\text {Ind }}^{2}+\sigma_{\mathrm{Err}}^{2}\right)$; $F_{\mathrm{PopHab}}$ is the correlation of genes within populations relative to habitats and is estimated as $\sigma_{\text {Pop }}^{2} /\left(\sigma_{\text {Pop }}^{2}+\sigma_{\text {Ind }}^{2}+\sigma_{\text {Err }}^{2}\right)$, where $\sigma_{\mathrm{Hab}}^{2}, \sigma_{\mathrm{Pop}}^{2}, \sigma_{\mathrm{Ind}}^{2}$ and $\sigma_{\mathrm{Err}}^{2}$ are the components of allelic frequencies variance for habitats, populations, among individuals within populations and within individuals, respectively. Note that $\sigma_{\mathrm{Ha},}^{2}$ the variance component for allelic frequencies among habitats, quantifies the amount of variance between habitats once all the underlying levels, in particular populations, have been accounted for. We tested whether $F_{\text {HabTotal }}$ and $F_{\text {PopHab }}$ differed from zero using the randomization functions implemented in HIERFSTAT. For $F_{\text {HabTotal }}$, whole populations were permuted among habitats, and for $F_{\mathrm{PopHab}}$, individuals were permuted among populations within habitat. $95 \%$ confidence intervals (CI) of the different $F$-statistics were obtained by bootstrapping $F_{\mathrm{ST}}$ values over loci. 


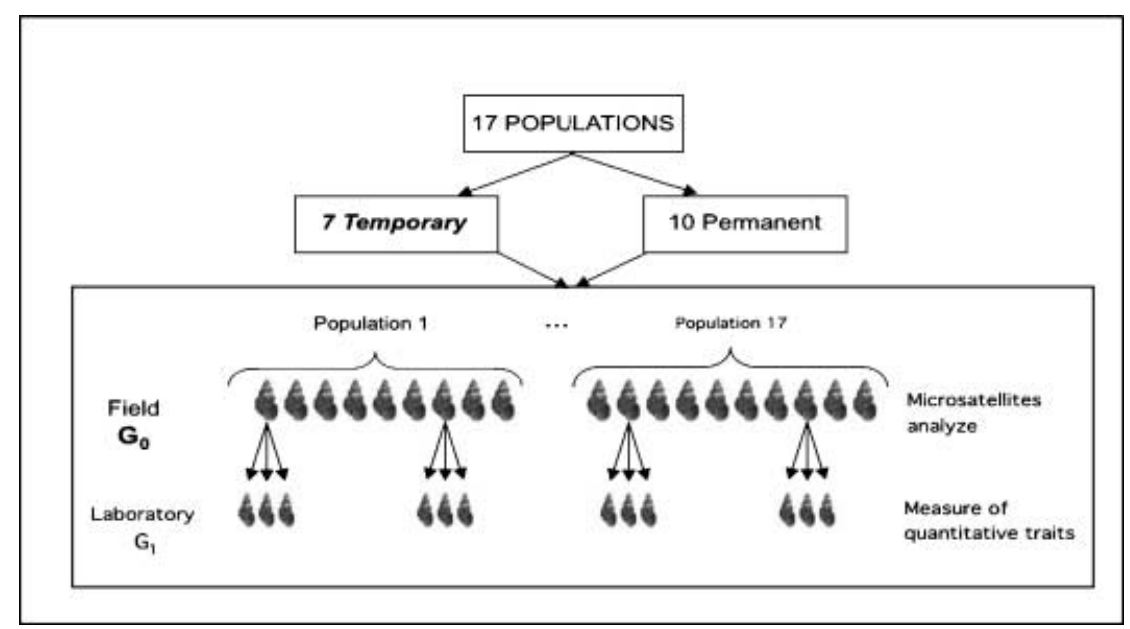

Fig. 2 Experimental design. The individuals collected in the field $\left(G_{0}\right)$ were genotyped. The first laboratory generation was used to estimate the quantitative traits.

Habitat-specific $F_{\mathrm{ST}}, F_{\mathrm{IS}}, H_{\mathrm{E}}$ and $R_{\mathrm{S}}$ and their differences were tested with permutations of populations between habitats using FSTAT 2.9.4 (Goudet 1995) (5000 randomizations). We tested for isolation by distance following Rousset (1997) with a Mantel-test between the matrices of pairwise $F_{\mathrm{ST}} /\left(1-F_{\mathrm{ST}}\right)$ and pairwise log transformed geographical distance using FSTAT 2.9.4.

\section{Quantitative traits}

Individuals were followed throughout their life cycle. A total of 16 growth traits - nine early quantitative traits (before maturity) and 11 late quantitative traits (after maturity) and four fecundity traits were measured for each $G_{1}$ snail.

In order to estimate growth, the shell size was measured using three parameters (length, width, and the ratio of both) at five dates: 3, 19, 33 days after hatching, at maturity and at 31 days after maturity. All size parameters were measured to the nearest $0.01 \mathrm{~mm}$ using an ocular micrometer on a binocular microscope. We also recorded age at maturity, determined when the first egg capsule was laid by selfing, the predominant mating system of this species (Trouvé et al. 2003).

Fecundity was estimated as the total number of capsules, the total number of eggs and the mean number of eggs per capsule laid 8 days after maturity. We also recorded the total number of eggs laid 31 days after maturity, an estimate of early reproduction (it was not possible practically to follow fecundity for a longer period).

Quantitative trait differences between habitats and between populations within habitat were tested with a nested analysis of variance (ANOvA) using the statistical software R (R Development Core Team 2004). Quantitative traits were analysed using the same hierarchical structure as molecular markers. We estimated the variance components between habitats $\left(\sigma_{\text {hab }}^{2}\right)$, between populations within habitats $\left(\sigma_{\text {Pop }}^{2}\right)$, between families within populations $\left(\sigma_{\text {Fam }}^{2}\right)$ and between individuals within families $\left(\sigma_{\text {Ind }}^{2}\right)$ with the method of restricted maximum likelihood (REML) (e.g. Lynch \& Walsh 1998). REML estimates were obtained using the package NLME for $\mathrm{R}$ (Pinheiro \& Bates 2000). Because G. truncatula is a predominant selfer (Trouvé et al. 2003, 2005), we assumed complete inbreeding in order to estimate the genetic and environmental part of the phenotypic variance. Thus, the genetic variance was estimated as $\sigma_{\text {Fam }}^{2}$, while environmental variance was estimated as $\sigma_{\text {Ind }}^{2}$ (Bonnin et al. 1996). Broad-sense heritability $\left(H^{2}\right)$ was estimated as: $H^{2}=\left(\sigma_{\text {Fam }}^{2}\right) /\left(\sigma_{\text {Fam }}^{2}+\sigma_{\text {Ind }}^{2}\right)$ (Schwaegerle et al. 1986; Venable \& Burquez 1989). Common garden experiments can overestimate heritabilities because the environmental variance is greatly reduced (Barton \& Turelli 1989). Houle (1992) suggested using the coefficient of genetic variation instead, as it does not depend on environmental variance while remaining standardized. The coefficient of genetic variation $\left(C V_{\mathrm{G}}\right)$ was measured as: $C V_{\mathrm{G}}=\left(\sigma_{\text {Fam }}^{2}\right)^{0.5} / m$, where $m$ is the population phenotypic mean (Bonnin et al. 1997).

$Q_{\mathrm{ST}}$ was estimated assuming complete selfing (Bonnin et al. 1996). Quantitative trait differentiation among habitats was estimated for each trait as $Q_{\text {HabTotal }}=\sigma_{\text {hab }}^{2} /\left(\sigma_{\text {hab }}^{2}+\right.$ $\left.\sigma_{\text {Pop }}^{2}+\sigma_{\text {Fam }}^{2}\right)$ while differentiation among populations within habitats was estimated as $Q_{\text {PopHab }}=\sigma_{\text {Pop }}^{2} /\left(\sigma_{\text {Pop }}^{2}+\sigma_{\text {Fam }}^{2}\right)$. We estimated mean $Q_{\mathrm{ST}}$ over traits as the sum of the numerators divided by the sum of the denominators of individual $Q_{\mathrm{ST}}$, after standardizing the sums of the variance components for each trait to 1 . This was done to avoid some traits having an undue influence on the overall average $Q_{\mathrm{ST}}$. Taking the ratio of the sums of numerators and denominators also corresponds to the way variance components of allele frequencies are combined across loci to obtain an estimate of $F_{\mathrm{ST}}$ over all loci (Weir 1996). We also computed the quantitative variation between habitats, distinguishing between the nine early and 11 late quantitative traits. Confidence intervals for the different mean 
Table 2 Within population molecular and quantitative variability. For each population and overall loci, the allelic richness $\left(R_{\mathrm{S}}\right)$, the gene diversity $\left(H_{\mathrm{E}}\right)$ and the inbreeding coefficient $\left(F_{\mathrm{IS}}\right)$ were estimated. For each population and over all quantitative traits, the genetic variance $\left(\sigma_{\text {Fam }}^{2}\right)$, the coefficient of genetic variance $\left(C V_{\mathrm{G}}\right)$ and the broad sense heritability $\left(H^{2}\right)$ were also measured. The mean of each measure, over all populations, is given with the standard errors in parentheses

\begin{tabular}{lcrrrrrrrrrrrrrrrrrr}
\hline & B & BO1 & BO2 & BO3 & Ch & Cv & LS & M & PO1 & PO2 & S1 & S2 & S4 & Si & T2 & T3 & T4 & Mean \\
\hline$R_{\mathrm{S}}$ & 1.14 & 1.77 & 1.34 & 1.13 & 1.59 & 1.67 & 1.03 & 1.04 & 1.07 & 1.14 & 1.57 & 1.79 & 2.31 & 1.33 & 1.22 & 1.30 & 1.43 & $1.40(0.08)$ \\
$H_{\mathrm{E}}$ & 0.08 & 0.41 & 0.19 & 0.08 & 0.32 & 0.36 & 0.02 & 0.02 & 0.04 & 0.07 & 0.32 & 0.40 & 0.82 & 0.17 & 0.12 & 0.17 & 0.23 & $0.22(0.05)$ \\
$F_{\mathrm{IS}}$ & 0.66 & 0.97 & 0.63 & 1.00 & 0.92 & 0.82 & 0.80 & 1.00 & 0.80 & 1.00 & 0.76 & 0.87 & 0.77 & 0.80 & 0.76 & 0.96 & 0.70 & $0.84(0.03)$ \\
$\sigma_{\text {Fam }}^{2}$ & 0.18 & 10.78 & 11.76 & 1.49 & 18.9 & 0.69 & 8.46 & 4.26 & 23.2 & 0.11 & 7.26 & 6.23 & 0.07 & 2.27 & 2.10 & 6.90 & 11.4 & $6.83(1.64)$ \\
$H^{2}$ & 0.27 & 0.28 & 0.25 & 0.20 & 0.31 & 0.31 & 0.19 & 0.15 & 0.42 & 0.28 & 0.20 & 0.39 & 0.24 & 0.27 & 0.10 & 0.18 & 0.24 & $0.25(0.02)$ \\
$C_{\mathrm{G}}$ & 0.07 & 0.09 & 0.06 & 0.05 & 0.11 & 0.13 & 0.10 & 0.05 & 0.15 & 0.07 & 0.05 & 0.13 & 0.07 & 0.06 & 0.03 & 0.05 & 0.06 & $0.07(0.01)$ \\
\hline
\end{tabular}

$Q_{S T}$ were obtained by bootstrapping individual trait values, assuming that these traits represented a random sample of all traits. The null hypothesis $F_{\mathrm{ST}}=Q_{\mathrm{ST}}$ was tested at two levels, between habitats $\left(F_{\text {HabTotal }}=Q_{\text {HabTotal }}\right)$, and within habitats $\left(F_{\mathrm{PopHab}}=Q_{\mathrm{PopHab}}\right) \cdot F_{\mathrm{ST}}$ over all loci was compared to $Q_{\mathrm{ST}}$ over all traits. We used two methods for comparing $Q_{\mathrm{ST}}$ and $F_{\mathrm{ST}}$. First, following Saint-Laurent et al. (2003), we considered $Q_{\mathrm{ST}}$ and $F_{\mathrm{ST}}$ different if their respective $95 \%$ CI did not overlap. Second, for the among habitat comparison, we reasoned as follows: under the null hypothesis that there is no effect of habitat on the difference between $Q_{\text {HabTotal }}$ and $F_{\text {HabTotal }}$ the observed difference should lie in the middle of the distribution of $Q_{\text {HabTotal }}{ }^{*}-$ $F_{\text {HabTotal }}{ }^{*}$, where $Q_{\text {HabTotal }}{ }^{*}$ and $F_{\text {HabTotal }}{ }^{*}$ were obtained after randomizations of the populations among habitats. We thus randomized populations among habitats 1000 times, and estimated from each of these randomized data sets $F_{\text {HabTotal }}{ }^{*}, Q_{\text {HabTotal }}{ }^{*}$ and $Q_{\text {HabTotal }}-F_{\text {HabTotal }}{ }^{*}$. An unbiased estimate of the probability that $Q_{\text {HabTotal }}$ is equal to $F_{\text {HabTotal }}$ vs. the alternative that $Q_{\mathrm{HabTotal}}$ is greater than $F_{\text {HabTotal }}$ is the proportion of times that the observed difference $\left(Q_{\text {HabTotal }}\right.$ $\left.-F_{\text {HabTotal }}\right)$ is larger than the difference obtained from randomizing populations among habitats. This allows us to test if the two subgroups chosen (based on habitat type information) yield a significantly larger $Q_{\mathrm{ST}} / F_{\mathrm{ST}}$ difference than two random subgroups of the same sizes

\section{Results}

The genotypic data are available from http://www2.unil.ch/ popgen/softwares/data/gtrunc_ec_06.dat. Individuals from population S4 suffered from a high mortality. Estimates of molecular and quantitative diversities for this population are based on four individuals only, while estimates from the other populations are based on at least 16 individuals for the molecular analysis and 10 families for the quantitative traits analysis. No isolation by distance was found $\left(R^{2}=0.017, P=0.12\right)$.

Within population variability summarized overall loci is given in Table 2. Averaged over all populations, allelic
Table 3 Within-habitat molecular variability and differentiation. Tests were performed between temporary water and permanent water habitat by randomization procedures using FSTAT2.9.4 (Goudet 1995)

\begin{tabular}{llll}
\hline & $\begin{array}{l}\text { Temporary } \\
\text { water }\end{array}$ & $\begin{array}{l}\text { Permanent } \\
\text { water }\end{array}$ & $P$ value \\
\hline$H_{\mathrm{E}}$ & 0.24 & 0.15 & 0.24 \\
$R_{\mathrm{S}}$ & 1.42 & 1.40 & 0.87 \\
$F_{\mathrm{IS}}$ & 0.83 & 0.82 & 0.94 \\
$F_{\mathrm{ST}}$ & 0.81 & 0.66 & 0.21 \\
\hline
\end{tabular}

$R_{S^{\prime}}$ allelic richness; $H_{\mathrm{E}}$ gene diversity; $F_{\mathrm{IS}}$, inbreeding coefficient.

richness and gene diversity are low $\left(R_{\mathrm{S}}=1.40\right.$ and $H_{\mathrm{E}}=$ 0.22 ), a finding similar to Trouvé et al. (2003). $F_{\mathrm{IS}}$ is very high for all populations and the overall $F_{\mathrm{IS}}$ is about 0.82 , providing an estimate of the selfing rate larger than $90 \%$, and comparable to results found previously (Trouvé et al. 2003). Averaged over all traits, within population genetic variances for quantitative traits vary widely from a low 0.18 to a high 23.2.

Broad sense heritabilities are more constant across traits, ranging from 0.1 to 0.42 , and coefficients of genetic variation range from 0.03 to 0.15 . There is a noteworthy lack of correlation between gene diversity and quantitative genetic variance $(R=-0.11, P=0.66)$. This remains true if we remove sample $S 4(R=0.13, P=0.66)$, and gene diversity does not correlate with other measures of quantitative variation, with or without population S4.

Estimation of $F_{\mathrm{ST}}, F_{\mathrm{IS}}, H_{\mathrm{E}}$ and $R_{\mathrm{S}}$ for each habitat are given in Table 3. No difference was found for these statistics between temporary and permanent water habitats (all $P>0.05)$, an indication that the two habitats do not differ in population size or extinction rates. Variance components of allelic frequencies per locus and gene diversities estimated at the level of the populations, the habitat and overall are given in Table 4 . While diversity is low within 


\begin{tabular}{lrllllllll}
\hline Locus & $\sigma_{\text {Hab }}^{2}$ & $\sigma_{\text {Pop }}^{2}$ & $\sigma_{\text {Ind }}^{2}$ & $\sigma_{\text {Err }}^{2}$ & $H_{\mathrm{T}}$ & $H_{\mathrm{H}}$ & $H_{\mathrm{P}}$ & $F_{\text {HabTotal }}$ & $F_{\text {PopHab }}$ \\
\hline 120 & 0.036 & 0.525 & 0.095 & 0.036 & 0.692 & 0.656 & 0.131 & 0.052 & 0.8 \\
121 & -0.047 & 0.578 & 0.135 & 0.025 & 0.691 & 0.738 & 0.160 & -0.069 & 0.783 \\
137 & -0.049 & 0.532 & 0.19 & 0.05 & 0.723 & 0.772 & 0.240 & -0.067 & 0.69 \\
129 & -0.017 & 0.592 & 0.152 & 0.037 & 0.764 & 0.781 & 0.189 & -0.023 & 0.759 \\
136 & -0.038 & 0.573 & 0.19 & 0.023 & 0.748 & 0.786 & 0.213 & -0.05 & 0.729 \\
19 & 0.016 & 0.51 & 0.134 & 0.035 & 0.695 & 0.679 & 0.169 & 0.023 & 0.751 \\
116 & -0.002 & 0.662 & 0.174 & 0.024 & 0.858 & 0.860 & 0.198 & -0.003 & 0.77 \\
Mean & -0.015 & 0.568 & 0.153 & 0.033 & 0.739 & 0.753 & 0.186 & -0.020 & 0.753 \\
\hline
\end{tabular}

Table 4 Variance components of allelic frequencies, gene diversity estimated overall $\left(H_{\mathrm{T}}\right)$, at the habitat $\left(H_{\mathrm{H}}\right)$ and at the population level $\left(H_{\mathrm{P}}\right)$, and population differentiation estimates for each locus and overall

Table 5 Mean phenotypic values (standard error) of all early and late traits in each habitat (permanent water and temporary water). Differences among habitats $(p$-Hab) and among populations nested in habitats ( $p$-Pop) were tested using hierarchical ANOvA

\begin{tabular}{|c|c|c|c|c|}
\hline Traits (units) & Permanent water & Temporary water & $p$-Hab & $p$-Pop \\
\hline \multicolumn{5}{|l|}{ Early traits } \\
\hline Length 3 days after hatching ( $\mathrm{mm})$ & $0.75(0.003)$ & $0.72(0.003)$ & 0.099 & $<0.001$ \\
\hline Width 3 days after hatching (mm) & $0.49(0.002)$ & $0.47(0.002)$ & 0.067 & $<0.001$ \\
\hline Ratio 3 days after hatching (mm) & $1.53(0.004)$ & $1.53(0.004)$ & 0.656 & $<0.001$ \\
\hline Length 19 days after hatching (mm) & $1.16(0.013)$ & $1.11(0.009)$ & 0.269 & $<0.001$ \\
\hline Width 19 days after hatching (mm) & $0.685(0.007)$ & $0.663(0.004)$ & 0.308 & 0.01 \\
\hline Ratio 19 days after hatching (mm) & $1.698(0.014)$ & $1.670(0.006)$ & 0.207 & 0.201 \\
\hline Length 33 days after hatching (mm) & $1.64(0.014)$ & $1.61(0.013)$ & 0.662 & $<0.001$ \\
\hline Width 33 days after hatching $(\mathrm{mm})$ & $0.867(0.006)$ & $0.850(0.006)$ & 0.520 & $<0.001$ \\
\hline Ratio 33 days after hatching (mm) & $1.889(0.005)$ & $1.899(0.006)$ & 0.683 & $<0.001$ \\
\hline \multicolumn{5}{|l|}{ Late traits } \\
\hline Length at maturity $(\mathrm{mm})$ & $3.44(0.014)$ & $3.64(0.017)$ & 0.007 & $<0.001$ \\
\hline Width at maturity $(\mathrm{mm})$ & $1.552(0.007)$ & $1.633(0.008)$ & 0.011 & $<0.001$ \\
\hline Ratio at maturity (mm) & $2.224(0.007)$ & $2.231(0.008)$ & 0.726 & $<0.001$ \\
\hline Length 31 days after maturity (mm) & $3.57(0.016)$ & $3.76(0.019)$ & 0.016 & $<0.001$ \\
\hline Width 31 days after maturity (mm) & $1.586(0.008)$ & $1.664(0.009)$ & 0.013 & $<0.001$ \\
\hline Ratio 31 days after maturity (mm) & $2.256(0.006)$ & $2.261(0.007)$ & 0.790 & $<0.001$ \\
\hline Age at maturity (days) & $99.22(1.281)$ & $111.89(1.285)$ & 0.010 & $<0.001$ \\
\hline Number of capsules & $2.71(0.149)$ & $2.14(0.143)$ & 0.011 & $<0.001$ \\
\hline Number of eggs & $4.31(0.079)$ & $3.79(0.073)$ & 0.074 & 0.188 \\
\hline Number of eggs per capsule & $1.61(0.036)$ & $1.81(0.036)$ & 0.029 & 0.004 \\
\hline Number of eggs laid in 30 days & $6.696(0.282)$ & $5.176(0.238)$ & 0.010 & $<0.001$ \\
\hline
\end{tabular}

populations $\left(H_{\mathrm{P}}=0.186\right)$, it is high at the habitat level $\left(H_{\mathrm{H}}=0.753\right)$, and overall $\left(H_{\mathrm{T}}=0.739\right)$. The seven loci show very similar patterns at all levels.

Mean values for all traits from each habitat are given in Table 5. Most traits differ significantly among populations within habitats. While early traits do not differ between habitats, most late traits do. Only two on the nine early traits appear marginally significant: the length and the width at three days after hatching $(P=0.099$ and $P=0.067$, respectively), which may reflect a small maternal effect. In permanent water habitat, individuals mature earlier and at a smaller size (length and width) than individuals living in temporary water habitats. At sexual maturity, individuals from temporary water habitat were about $3.64 \mathrm{~mm}$ long and about 112 days old, while individuals from permanent water habitat were only $3.44 \mathrm{~mm}$ long and 99 days old
(Table 5). Individuals from permanent water habitat are still smaller 31 days after maturity (Table 5). They lay more capsules (2.71 in permanent water habitat vs. 2.14 in temporary water habitat) but fewer eggs per capsule than individuals from temporary water habitat and they lay marginally more eggs during the first 8 days after maturity but significantly more during the first month following maturity (6.70 eggs in permanent water habitat vs. 5.18 in temporary water habitat) (Table 5).

Within habitats, molecular differentiation is very strong and highly significant, $F_{\text {PopHab }}=0.75(P<0.01,95 \% \mathrm{CI}$ : $0.72-0.78$, Table 6). A high but smaller mean quantitative trait differentiation is found: mean $Q_{\text {PopHab }}=0.31$ (95\% CI: 0.25-0.39, Table 6). Within habitats, mean $Q_{\text {PopHab }}$ over all traits is significantly lower than $F_{\text {PopHab }}$ over all loci (Table 6, Fig. 3). 


\begin{tabular}{|c|c|c|c|c|c|c|}
\hline Quantitative traits & $\sigma_{\text {hab }}^{2}$ & $\sigma_{\text {pop }}^{2}$ & $\sigma_{\mathrm{fam}}^{2}$ & $\sigma_{\text {ind }}^{2}$ & $Q_{\text {HabTotal }}$ & $Q_{\text {PopHab }}$ \\
\hline L. $3^{*}$ & 1.28 & 11.75 & 17.79 & 19.50 & 0.04 & 0.39 \\
\hline W. $3^{*}$ & 0.95 & 3.67 & 11.15 & 10.38 & 0.06 & 0.25 \\
\hline R. $3^{*}$ & 0.00 & 13.88 & 31.01 & 0.00 & 0.00 & 0.31 \\
\hline L. $19^{*}$ & 7.19 & 53.55 & 219.06 & 756.24 & 0.03 & 0.20 \\
\hline W.19* & 1.26 & 7.19 & 50.30 & 240.62 & 0.02 & 0.13 \\
\hline R.19* & 2.59 & 3.03 & 31.55 & 967.07 & 0.07 & 0.09 \\
\hline L. $33^{*}$ & 0.38 & 159.14 & 546.16 & 665.42 & 0.00 & 0.23 \\
\hline W.33* & 0.02 & 27.14 & 106.69 & 146.34 & 0.00 & 0.20 \\
\hline R.33* & 0.00 & 15.16 & 55.16 & 133.93 & 0.00 & 0.22 \\
\hline L.MAT ${ }^{*}$ & 77.83 & 164.38 & 85.17 & 656.19 & 0.24 & 0.66 \\
\hline W.MAT* & 13.15 & 32.46 & 21.83 & 181.67 & 0.19 & 0.60 \\
\hline R.MAT* & 0.02 & 10.22 & 22.19 & 177.66 & 0.00 & 0.32 \\
\hline L.MAT31* & 101.76 & 177.84 & 120.10 & 640.61 & 0.25 & 0.60 \\
\hline W.MAT31* & 18.31 & 29.17 & 24.03 & 168.31 & 0.26 & 0.55 \\
\hline R.MAT31* & 0.00 & 14.46 & 7.08 & 114.06 & 0.00 & 0.67 \\
\hline AGE.MAT & 50.97 & 61.62 & 141.07 & 456.87 & 0.20 & 0.30 \\
\hline NUMBE & 0.14 & 0.12 & 0.22 & 1.95 & 0.30 & 0.36 \\
\hline NUMBC & 0.08 & 0.10 & 1.12 & 7.06 & 0.06 & 0.08 \\
\hline NUMBE.C & 0.02 & 0.01 & 0.03 & 0.45 & 0.27 & 0.31 \\
\hline \multirow[t]{4}{*}{ FEC.31 } & 0.61 & 0.96 & 4.52 & 22.48 & 0.10 & 0.18 \\
\hline & & & Mean & $Q_{\mathrm{ST}}$ & 0.14 & 0.31 \\
\hline & & & & & $0.07-0.20$ & $0.25-0.39$ \\
\hline & & & Overall & $F_{\mathrm{ST}}$ & -0.02 & 0.76 \\
\hline
\end{tabular}

Table 6 REML variance component for quantitative traits: between habitats, $\sigma_{\text {hab }}^{2}$ between populations within habitats, $\sigma_{\text {pop }}^{2}$ between families within populations, $\sigma_{\text {pop, }}^{2}$ between individuals within families, $\sigma_{\text {ind }}^{2}$. For the traits specified by $a *$, the component of variance values shown in the table are multiplied by $10^{4}$. The quantitative differentiation between habitats $\left(Q_{\text {HabTotal }}\right.$ ) and between populations within habitats $\left(Q_{\mathrm{PopHab}}\right)$ is given for each trait and over all traits. Confidence intervals (CI), in italics, are obtained by bootstraps over traits. Corresponding values for $F_{\mathrm{ST}}$ are also reported

There is no extra molecular differentiation among habitats as compared to among populations within habitats $\left(F_{\text {HabTotal }}=-0.02, P=0.79,95 \%\right.$ CI: $-0.05-0.01$, Table 6). Thus, the habitat type does not generate extra molecular variance, and pairs of populations between habitats are no more differentiated than pairs within each habitat. In contrast, there is a significant component of variance among habitats for quantitative traits (mean $Q_{\text {HabTotal }}=0.14,95 \%$ CI: $0.07-0.20$, permutation test $P=0.018$, Fig. 4 and Table 6). Overall therefore, mean $Q_{\text {HabTotal }}$ (over all traits) is significantly higher than $F_{\text {HabTotal }}$ (over all loci) between habitats (permutation test $P=0.018$, Fig. 4).

Among habitats, the pattern $Q_{\mathrm{ST}}>F_{\mathrm{ST}}$ is mainly due to late traits since $Q_{\text {LATEHabTotal }}=0.28$ (95\% CI: 0.19-0.34) while $Q_{\text {EARLYHabTotal }}=0.03$ (95\% CI: 0.002-0.06, Fig. 3). Figure 4 shows the null distributions of $Q_{\text {LATEHabTotal }}$ $F_{\text {HabTotal }}$, and the difference $Q_{\text {LATEHabTotal }}-F_{\text {HabTotal }}$. While $F_{\text {HabTotal }}$ does not differ from $0(P=0.678)$, it is clear that both $Q_{\text {LATEHabTotal }}$ and the difference $Q_{\text {LATEHabTotal }}-F_{\text {HabTotal }}$ are different from $0(P=0.014$ in both cases $)$. A similar result is obtained over all traits $(P=0.018)$, while for early traits, both $Q_{\text {EARLYHabTotal }}$ and $Q_{\text {EARLYHabTotal }}-F_{\text {HabTotal }}$ do not differ significantly from 0 ( $P=0.343$ for both). Within habitats, the pattern $Q_{\mathrm{ST}}<F_{\mathrm{ST}}$ holds for both early and late traits $\left(Q_{\text {EARLYPopHab }}=0.23,95 \% \mathrm{CI}: 0.18-0.28\right.$ and $Q_{\text {LATEPopHab }}=0.45,95 \%$ CI: $\left.0.33-0.56\right)$ but $Q_{\text {LATEPopHab }}$ is significantly higher than $Q_{\text {EARLYPopHab }}$ (Fig. 3).

\section{Discussion}

The main finding of this study is that $Q_{\mathrm{ST}}>F_{\mathrm{ST}}$ between permanent and temporary water habitats, indicating selection for different optima in the two contrasted habitats and local adaptation. This pattern appears to be mainly driven by differences in quantitative traits among habitats in the late stages of the life cycle. We first discuss the lack of association between estimates of molecular and quantitative diversity.

Molecular diversity is often used as a surrogate for quantitative diversity to determine the evolutionary potential of small populations (Frankham 1999). Given the low molecular genetic diversity in Galba truncatula populations (Trouvé et al. 2003, 2005; this study), the differences in quantitative trait values between temporary and permanent water habitats may be surprising. This low variability is due to small effective population sizes caused by recurrent bottlenecks and a strong selfing rate, as shown by Trouvé et al. (2005). Empirical support for the relationship between molecular and quantitative variability is weak at best, as demonstrated by Reed \& Frankham (2001). Our results are in accordance with this observation: we find a lack of correspondence between molecular and quantitative variability both within populations and among habitats. A study by McKay et al. (2001) showed a pattern similar to ours in the rare endemic plant Arabis fecunda: 19 populations 


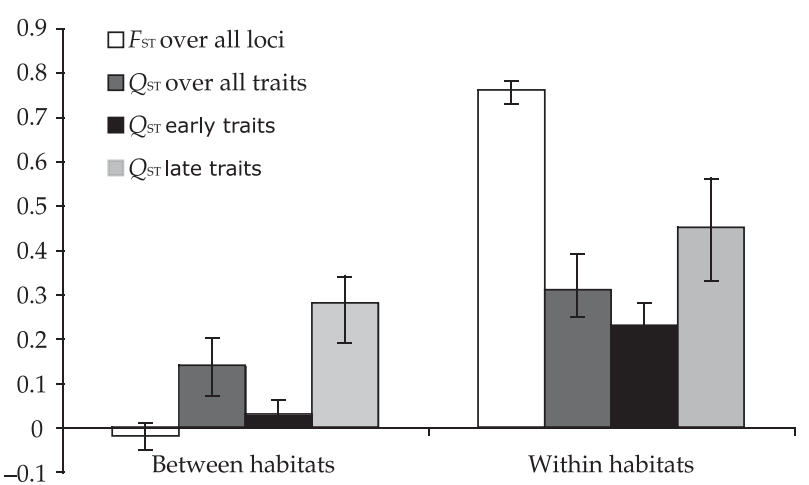

Fig. 3 Comparison between molecular $\left(F_{\mathrm{ST}}\right.$ over all loci, white bars) and quantitative differentiation $\left(Q_{\mathrm{ST}}\right.$ over all traits, dark grey bars) among and within habitats. $Q_{\mathrm{ST}}$ computed with early traits and late traits are represented in black and pale grey, respectively. Error bars represent the $95 \%$ confidence intervals. The selective trait divergence between habitats $\left(Q_{\mathrm{ST}}>F_{\mathrm{ST}}\right)$ is only apparent on late traits.

from two different climatic areas separated by $100 \mathrm{~km}$ maintain strong quantitative differences despite small effective population sizes and extremely low genetic diversity. However, as populations belonging to each climatic area are clustered $100 \mathrm{~km}$ apart, other ecological factors could be the cause of the observed pattern. We found results similar to McKay et al. (2001) but with no geographical confounding effect since our populations are randomly distributed with respect to habitat type.

Can our result be attributed to confounding factors other than water permanency in the ponds? A first potential artefact could arise from maternal and/or environmental effects, which would inflate the between-families and between-populations components of variance (Mousseau \& Fox 1998). Maternal effects are most likely to operate early in the life of organisms, and should vanish with age (Mitchell-Olds \& Bergelson 1990; Wolf 2000). However, the significant $Q_{\mathrm{ST}}-F_{\mathrm{ST}}$ differences between habitats only appear on traits from the late part of the life cycle and related to fitness: size and age at maturity, and fecundity. Maternal effects are thus unlikely to explain the observed pattern. A second potential artefact may stem from the mode of reproduction through selfing of G. truncatula during the experiment. Some authors have suggested that selfing might alter the expected relationship between $Q_{\mathrm{ST}}$ and $F_{\mathrm{ST}}$ in unpredictable ways (Yang et al. 1996; Merilä \& Crnokrak 2001). Selfing, through its effect on linkage disequilibrium (Latta 1998), could either reduce or enhance the differences observed between $Q_{\mathrm{ST}}$ and $F_{\mathrm{ST}}$. However, a simulation study by Le Corre \& Kremer (2003) with purely additive traits under various selection regimes showed that the predicted relationships between $F_{\mathrm{ST}}$ and $Q_{\mathrm{ST}}$ hold for selfing populations. Goudet \& Büchi (2006) looked at
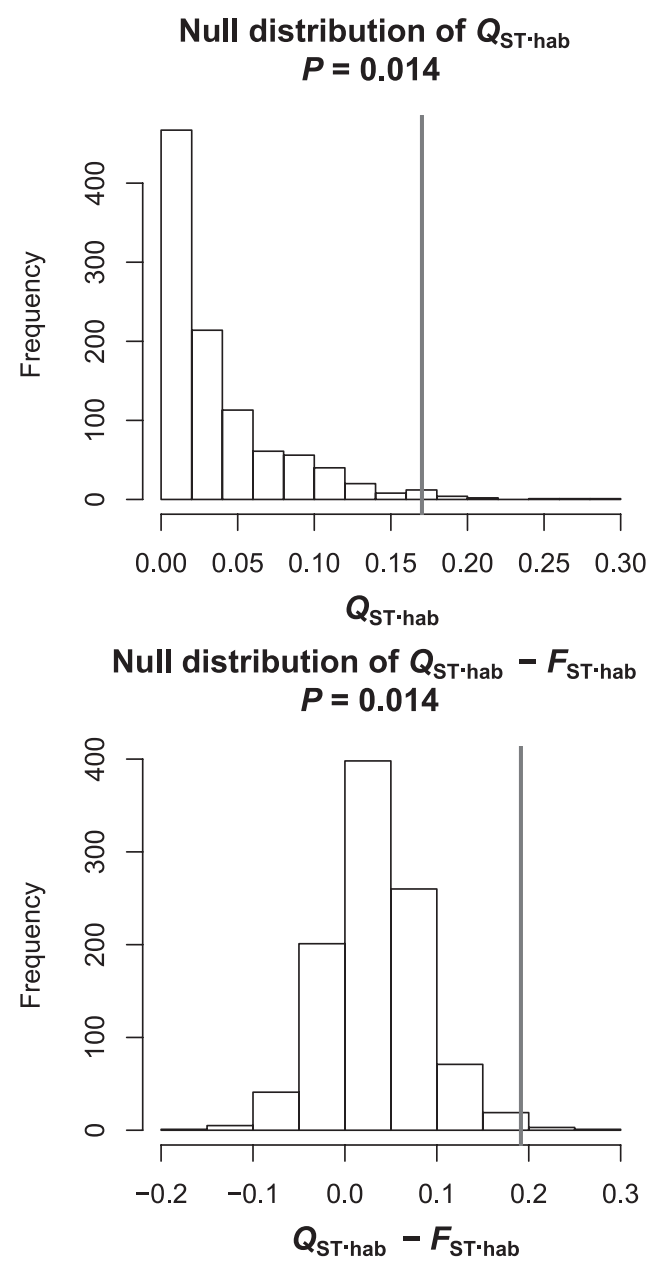

Null distribution of $\boldsymbol{F}_{\mathrm{ST} \text {-hab }}$ $P=0.678$

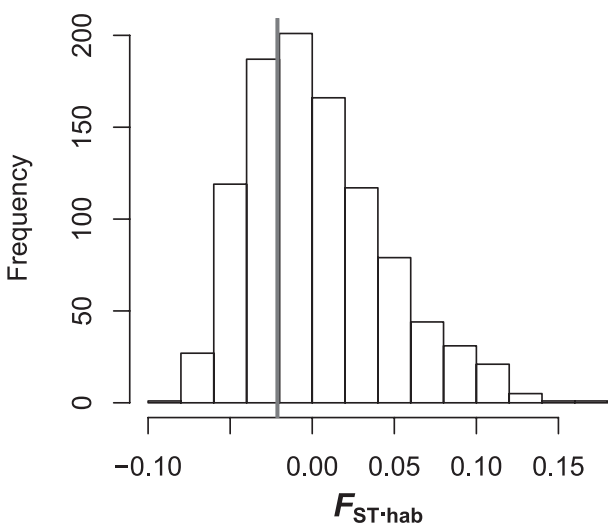

Fig. 4 Null distributions of $Q_{\text {LATEHabTotal }}, F_{\text {HabTotal }}$ and the difference $Q_{\text {LATEHabTotal }}-F_{\text {HabTotal }}$ obtained by permuting whole populations among habitats a 1000 time. The vertical bar represents the observed values of $Q_{\text {LATEHabTotal }}, F_{\text {HabTotal }}$ and their difference. The trait divergence $\left(Q_{\mathrm{ST}}\right)$ between the two habitat types is significantly higher than what would be observed by randomly assigning populations to two distinct subgroups of the same size. It is not the case for neutral molecular divergence $\left(F_{\mathrm{ST}}\right)$, suggesting that trait differences were driven by divergent selection between habitats $\left(Q_{\mathrm{ST}}>F_{\mathrm{ST}}\right)$. 
the effect of inbreeding on $Q_{\mathrm{ST}}-F_{\mathrm{ST}}$ for a trait with nonadditive gene action. They showed that dominance tends to lower $Q_{\mathrm{ST}}$ compared to $F_{\mathrm{ST}}$ but that the effect of dominance vanishes under high inbreeding. Finally, an empirical and simulation study by Porcher et al. (2006) on Arabidopsis thaliana, a self-fertilizing species, also found the pattern $Q_{\mathrm{ST}}>F_{\mathrm{ST}}$ to be a robust indication of divergent selection. Thus selfing and nonadditive gene effects are unlikely to give rise to the observed pattern $Q_{\mathrm{ST}}>F_{\mathrm{ST}}$, which therefore gives robust evidence of divergent selection between temporary and permanent habitats.

By contrast, as nonadditive gene action (i.e. dominance or epistasis) tends to reduce $Q_{\mathrm{ST}}$ compared to $F_{\mathrm{ST}}$ (Toro \& Caballero 2005; Goudet \& Büchi 2006), it is more difficult to draw inferences from the pattern $Q_{\mathrm{ST}}<F_{\mathrm{ST}}$ that we observed within habitats. It might be that homogenizing selection tends to maintain populations from the same habitat at similar values of the life history traits measured. However, in a highly selfing species like G. truncatula, we must also consider the possibility of strong epistatic interaction among loci, which would lead to the same pattern $Q_{\mathrm{ST}}<F_{\mathrm{ST}}$ (Whitlock 1999).

Finally, it could be argued that our estimate of $F_{\text {HabTotal }}$ is an underestimate because gene diversity at the level of the habitats is high $\left(H_{\mathrm{H}}=0.753\right.$, Table 4$)$. Indeed, with such a high diversity within habitats, $F_{\mathrm{HabTotal}}$ is constrained to be less than $\left(1-H_{\mathrm{H}}\right)=0.247$ (Hedrick 2005; note that the correction for the number of populations is not necessary here as we used estimators of gene diversities already corrected for the number of samples, see Weir 1996). However, five out of the seven loci show a negative component of variance among habitats, and for the remaining two, this component is much smaller than the potential maximum $\left(1-H_{\mathrm{H}}=0.247\right)$ and not significantly different from zero (Tables 4, $P$ values for $\sigma_{\text {hab }}^{2}$ of Locus L20 and L9 are 0.24 and 0.49 , respectively). Thus, the observed lack of structure at neutral markers among habitats is not an artifact: once the effect of populations within habitats is accounted for, there is no further effect of the habitat on allelic frequencies.

Overall, the finding $Q_{\mathrm{ST}}>F_{\mathrm{ST}}$ between habitats seems to stem from the ecological pressures specific to each habitat type. Intraspecific variation in size and growth related to environment has already been reported. Variation in growth rate is well known to follow latitudinal or altitudinal selective gradients in insects (for instance Drosophila, Gilchrist et al. 2001) and amphibians (for instance Ranatemporaria, Lindgren \& Laurila 2005). In R. temporaria, individuals were found to develop faster in northern than in southern populations (Laugen et al. 2002; Laurila et al. 2002). Moreover, using the $Q_{\mathrm{ST}}-F_{\mathrm{ST}}$ comparison, Palo et al. (2003) showed that selection is responsible for this latitudinal divergence in growth rate. However, these authors only studied early developmental traits (age and weight at metamorphosis, growth rate to metamorphosis), which may be influenced by maternal effects (Mousseau \& Fox 1998). Here, we made a distinction between early and late traits and found divergence between habitats on late traits only (size and age at maturity, size 31 days after maturity and fecundity).

The pattern $Q_{\mathrm{ST}}>F_{\mathrm{ST}}$ for late traits but not for early traits requires an explanation. The obvious factor differing between temporary water and permanent water habitats is the probability of drying out. Either temporary water habitat should select for individuals more resistant to desiccation than permanent water habitat or populations from temporary water habitats should often go extinct. But similar molecular diversity levels in permanent and temporary water habitats suggest that populations from temporary habitats are not more affected by extinctions than populations from permanent ones. Thus, individuals from temporary water habitats are likely to have adapted to dry conditions. Studies on other snail species have previously shown size to be positively related to desiccation resistance and in particular, juvenile stages have been shown to be extremely sensitive to a dry environment (e.g. Dudgeon 1981; Facon et al. 2004). We observe (E. Chapuis and J. Goudet unpublished) that the juvenile resistance is quasi null for $G$. truncatula individuals from both habitats. Thus, as there is no variance in fitness for juveniles confronted with drought in both habitats, no selection is possible. This is consistent with our observation that $Q_{\mathrm{ST}}>F_{\mathrm{ST}}$ for late traits. In order to investigate this question further, it would be necessary to test experimentally how juveniles and adults from each habitat resist desiccation.

According to the theory of McArthur \& Wilson (1967), we expect individuals living in temporary (supposedly variable) habitats to reach sexual maturity earlier, at smaller size and to be more fecund than individuals from permanent (supposedly stable) habitats. However, we observed the opposite pattern: individuals from permanent water habitats mature younger, at a smaller size and lay more eggs than individuals from temporary water habitats. This difference is also observed in the wild, where we found individuals from permanent water habitats to be on average smaller than individuals from temporary water habitats (E. Chapuis, personal observation). It has been pointed out that important aspects of the species ecology, such as stress, were missing from the theory of McArthur \& Wilson (1967). For plants, Grime (1977) suggested a classification according to three life history strategies triggered by two external factors; stress and disturbance. First, plants can live in stressful conditions such as extreme temperatures or low water, light or minerals availability, and this can affect their productivity. Second, parasites, predators or abiotic factors such as fire and wind can destroy the plant biomass. While a stressful and disturbed habitat is unlikely to sustain a plant population for long, 
the other combinations of stress and disturbance lead Grime (1977) to suggest three strategies. In predictive stressful habitats (high stress and low disturbance, akin to extreme K-selection in McArthur \& Wilson 1967), plants should reduce vegetative and reproductive vigour to adapt to predictable stress. In ruderal habitats (low stress and high disturbance, akin to extreme r-strategy in MacArthur \& Wilson 1967), plants should have a short life span and high seed production. And in competitive habitats (low stress and low disturbance, intermediate between r- and K-strategies sensu McArthur \& Wilson 1967), plants should maximize growth.

This model has been adapted to freshwater snails by Dillon (2000), who suggested the following. In rich but disturbed environments, such as eutrophic bodies of water, an R-strategy with high reproductive output (where $\mathrm{R}$ stands for reproduction), as in ruderal plants, should develop. In stressful but predictable habitats, an S-strategy (S for stress) should develop, where individuals reduce their growth and/or reproduction. In our study, populations from temporary water habitat could belong to this category, assuming that periods of drought stress are reasonably predictable. Last, in stable and unstressful habitats, Dillon (2000) suggests that U-strategies (U for undifferentiated) should evolve. According to Dillon (2000), any combination of life history attributes could emerge from this category. In our case, populations from the permanent water habitat would belong to this last category. Under Dillon's classification, there is no prediction for the type of traits that should evolve in permanent water habitat. However, in temporary water habitat, Dillon's classification predicts an S-strategy, which is consistent with the late maturity and low fecundity that we observed in this habitat.

In this study, we have demonstrated a much higher differentiation for quantitative traits occurring late in the life cycle than for molecular markers among temporary and permanent habitats and showed that this is likely due to an adaptive response to recurrent drought in temporary water habitats. We hope that this study illustrates how the $Q_{\mathrm{ST}}-F_{\mathrm{ST}}$ comparisons can give reliable evidence of the impact of selection in natura and the local adaptation phenomenon, providing many populations are sampled and relevant ecological factors can be identified.

\section{Acknowledgements}

We are grateful to D. Croll for field assistance, N. Juillet for statistical help, G. Evanno, P. Fontanillas, N. Perrin, G. Martin, V. Ravigné, $P$. Taberlet and four anonymous reviewers for comments that helped improve the manuscript, and L. Handley for comments and checking the English. Funding of this study was provided by a Swiss National Science Foundation National Grant (3100-68325.2) to J.G. and S.T.

\section{References}

Barton NH, Turelli M (1989) Evolutionary quantitative genetics: how little do we know? Annual Review of Genetics, 23, 337370.

Bonnin I, Huguet T, Gherardi M, Prosperi JM, Olivieri I (1996) High level of polymorphism and spatial structure in a selfing plant species, Medicago truncatula (Leguminosae), shown using RAPD markers. American Journal of Botany, 83, 843-855.

Bonnin I, Prosperi JM, Olivieri I (1997) Comparison of quantitative genetic parameters between two natural populations of a selfing plant species, Medicago truncatula Gaertn. Theoretical Applied Genetics, 94, 641-651.

Bousset L, Henry P-Y, Jarne P (2004) Population biology. Molecular Ecology, 13, 2023-2036.

Brown KM (1985) Intraspecific life history variation in a pond snail: the roles of population divergence and phenotypic plasticity. Evolution, 39, 387-395.

Byers DL (2005) Evolution in heterogeneous environments and the potential of maintenance of genetic variation in traits of adaptive significance. Genetica, 123, 107-124.

Dillon RT Jr (2000) The Ecology of Freshwater Molluscs. Cambridge University Press, Cambridge, UK.

Dudgeon D (1981) Aspects of the desiccation tolerance of four species of benthic mollusca from plover cove reservoir, Hong Kong. Veliger, 24, 267-271.

Facon B, Machline E, Pointier JP, David P (2004) Variation in desiccation tolerance in freshwater snails and its consequences for invasion ability. Biological Invasions, 6, 283-293.

Frankham R (1999) Quantitative genetics in conservation biology. Genetical Research Cambridge, 74, 237-244.

Fretter V, Peake J (1975) Pulmonates, Vol. 1, Functional Anatomy and Physiology, Academic Press Inc., London.

Gilchrist GW, Huey RB, Serra L (2001) Rapid evolution of wing size clines in Drosophila subobscura. Genetica, 112, 273-286.

Gillespie JH, Turelli M (1989) Genotype-environment interactions and the maintenance of polygenic variation. Genetics, 121, 129138.

Gomez-Mestre I, Tejedo M (2004) Contrasting patterns of quantitative and neutral genetic variation in locally adapted populations of the natterjack toad, Bufo calmita. Evolution, 58, 2343-2352.

Goudet J (1995) FSTAT: a computer program to calculate $F$-statistics. Journal of Heredity, 86, 485-486.

Goudet J (2005) HIERFSTAT, a package for $\mathrm{R}$ to compute and test hierarchical F-statistics. Molecular Ecology Notes, 5, 184-186.

Goudet J, Büchi L (2006) The effects of dominance, regular inbreeding and sampling design on $Q_{\mathrm{ST}}$ an estimator of population differentiation for quantitative traits. Genetics, 172, 1337-1347.

Grime JP (1977) Evidence for the existence of three primary strategies in plants and its relevance to ecological and evolutionary theory. American Naturalist, 111, 1169-1194.

Hartl DL, Clark AG (1997) Principles of Population Genetics, 3rd edn. Sinauer Associates, Sunderland, Massachusetts.

Hedrick PW (2005) A standardized genetic differentiation measure. Evolution, 59, 1633-1638.

Hedrick PW (2006) Genetic polymorphism in heterogeneous environments: the age of genomics. The Annual Review of Ecology, Evolution and Systematics, 37, 67-93.

Henry P-Y (2002) Dynamique des populations et évolution du système de reproduction. Etude chez le gastéropode Physa acuta (Pulmoné), PhD Thesis, Université de Montpellier II, France. 
Henry P-Y, Bousset L, Sourrouille P, Jarne P (2005) Partial selfing, ecological disturbance and reproductive assurance in an invasive freshwater snail. Heredity, 95, 428-436.

Houle D (1992) Comparing evolvability and variability of quantitative traits. Genetics, 130, 195-204.

Kawecki TJ, Ebert D (2004) Conceptual issues in local adaptation. Ecology Letters, 7, 1225-1241.

Kendall SB (1949) Bionomics of Limnaea truncatula and the Parthenitae of Fasciola hepatica under Drought Conditions. Journal of Helminthology, 23, 57-68.

Kendall SB (1953) The life story of Limnaea truncatula under Laboratory Conditions. Journal of Helminthology, 27, 17-28.

Kimura M (1983) The Neutral Theory of Molecular Evolution. Cambridge University Press, New York.

Latta RG (1998) Differentiation of allelic frequencies at quantitative trait loci affecting locally adapted traits. American Naturalist, 151, 283-292.

Laugen AT, Laurila A, Merilä J (2002) Maternal and genetic contributions to geographical variation in Rana temporaria larval life history traits. Biological Journal of the Linnean Society, 76, 6170.

Laurila A, Karttunen S, Merilä J (2002) Adaptive phenotypic plasticity and genetics of larval life histories in two Rana temporaria populations. Evolution, 56, 617-627.

Le Corre V, Kremer A (2003) Genetic variability at neutral markers, quantitative trait loci and trait in a subdivided population under selection. Genetics, 164, 1205-1219.

Lenormand T (2002) Gene flow and the limits to natural selection. Trends in Ecology \& Evolution, 17, 183-189.

Levene H (1953) Genetic equilibrium when more than one niche is available. American Naturalist, 87, 331-333.

Lindgren B, Laurila A (2005) Proximate causes of adaptive growth rates: growth efficiency variation among latitudinal populations of Rana temporaria. Journal of Evolutionary Biology, 18, 820828.

Lynch M, Pfrender M, Spitze K et al. (1999) The quantitative and molecular genetic architecture of a subdivided species. Evolution, 53, 100-110.

Lynch M, Walsh B (1998) Genetics and Analysis of Quantitative Traits. Sinauer Associates, Sunderland, Massachusetts.

McArthur RH, Wilson EO (1967) The Theory of Island Biogeography. Princeton University Press, Princeton, New Jersey.

McKay JK, Bishop JG, Lin J-Z et al. (2001) Local adaptation across a climatic gradient despite small effective population size in the rare sapphire rockress. Proceeding of the Royal Society of London. Series B, Biological Sciences, 268, 1715-1721.

McKay JK, Latta RG (2002) Adaptive population divergence: markers, QTL and traits. Trends in Ecology E Evolution, 17, 285-291.

Merilä J, Crnokrak P (2001) Comparison of genetic differentiation at marker loci and quantitative traits. Journal of Evolutionary Biology, 14, 892-903.

Mitchell-Olds T, Bergelson J (1990) Statistical genetics of an annual plant, Impatiens capensis. II. Natural selection. Genetics, 124, 417-421.

Morel-Vareille R (1973) Contribution à l'étude du cycle biologique de Lymnaea truncatula, Müller dans le Nord-Ouest du Limousin. Revue Médicale, vétérinaire, 124, 1447-1457.

Mousseau A, Fox CW (1998) The adaptive significance of maternal effects. Trends in Ecology and Evolution, 13, 403-407.

Nei M (1987) Molecular Evolutionary Genetics. Columbia University Press, New York.
Palo JU, O’Hara B, Laurila A, Primmers R, Merilä J (2003) Latitudinal divergence of common frog (Rana temporaria) life history traits by natural selection: evidence from a comparison of molecular and quantitative genetic data. Molecular Ecology, 12, 1963-1978.

Peters BG (1938) Habitats of L. truncatula in England and Wales during dry seasons. Journal of Heminthology, 16, 213-260.

Pinheiro J, Bates DM (2000) Mixed Effects Models in S and S-PLUS. Springer, New York.

Porcher E, Giraud T, Lavigne C (2006) Genetic differentiation of neutral markers and quantitative traits in predominantly selfing metapopulations: confronting theory and experiments with Arabidopsis thaliana. Genetical Research Cambridge, 87, 1-12.

R Development Core Team (2004) R: a language and environment for statistical computing. R Foundation for Statistical Computing, Vienna, Austria URL http://www.R-project.org.ISBN3-90005100-3.

Reed DH, Frankham R (2001) How closely correlated are molecular and quantitative measures of genetic variation? A meta-analysis. Evolution, 55, 1095-1103.

Reznick D, Bryant MJ, Bashey F (2002) r- and K- selection revisited: the role of population regulation in life-history evolution. Ecology, 83, 1509-1520.

Rousset F (1997) Genetic differentiation and estimation of gene flow from $F$-statistics under isolation by distance. Genetics, 145, 1219-1228.

Saint-Laurent R, Legault M, Bernatchez L (2003) Divergent selection maintains adaptive differentiation despite high gene flow between sympatric rainbow smelt ecotypes (Osmerus mordax Mitchill). Molecular Ecology, 12, 315-330.

Schwaegerle KE, Garbutt K, Bazzaz FA (1986) Differentiation among nine populations of Phlox. I. Electropheric and quantitative variation. Evolution, 40, 506-517.

Slatkin M (1985) Gene flow in natural populations. Annual Review of Ecology and Systematics, 16, 393-430.

Spitze K (1993) Population structure in Daphnia obtusa: quantitative genetic and allozymic variation. Genetics, 135, 367-374.

Stearns SC (1976) Life-history tactics: a review of the ideas. The Quarterly Review of Biology, 51, 3-47.

Stearns SC (1977) The evolution of life history traits: a critique of the theory and a review of the data. Annual Review of Ecology and Systematics, 8, 145-171.

Steinger T, Haldimann P, Leiss A, Müller-Schärer H (2002) Does natural selection promote population divergence? A comparative analysis of population structure using amplified fragment length polymorphism markers and quantitative traits. Molecular Ecology, 11, 2583-2590.

Stenøien HK, Fenster CB, Tonteri A, Savolainen O (2005) Genetic variability in natural populations of Arabidopsis thaliana in northern Europe. Molecular Ecology, 14, 137-148.

Storz JF (2002) Contrasting patterns of divergence in quantitative traits and neutral DNA markers: analysis of clinal variation. Molecular Ecology, 11, 2537-2551.

Toro MA, Caballero A (2005) Characterization and conservation of genetic diversity in subdivided populations. Philosophical Transactions of the Royal Society of London. Series B, Biological Sciences, 360, 1367-1378.

Trouvé S, Degen L, Goudet J (2005) Ecological components and evolution of selfing in the freshwater snail Galba truncatula. Journal of Evolutionary Biology, 18, 358-370.

Trouvé S, Degen L, Meunier C et al. (2000) Microsatellites in the hermaphroditic snail, Lymnaea truncatula, intermediate host of the liver fluke, Fasciola hepatica. Molecular Ecology, 9, 1661-1686. 
Trouvé S, Degen L, Renaud F, Goudet J (2003) Evolutionary implications of high selfing rate in the freshwater snail Lymnaea truncatula. Evolution, 57, 2303-2314.

Venable LD, Burquez AM (1989) Quantitative genetics of size, shape, life-history, and fruit characteristics of the seed heteromorphic composite Heterosperma pinnatum. I. Variation within and among populations. Evolution, 43, 113-124.

Volis S, Yakubov B, Shulgina I, Ward D, Mendlinger S (2005) Distinguishing adaptive from nonadaptive genetic differentiation: comparison of $Q_{\mathrm{ST}}$ and $F_{\mathrm{ST}}$ at two spatial scales. Heredity, 95, 466-475.

Weir BS (1996) Genetic Data Analysis. II. Sinauer Associates, Sunderland, Massachusetts.

Weir BS, Cockerham CC (1984) Estimating F-statistics for the analysis of population structure. Evolution, 38, 1358-1370.

Whitlock MC (1999) Neutral additive genetic variance in a metapopulation. Genetical Research Cambridge, 74, 215-221.

Williams GC (1966) Natural selection, the cost of reproduction and a refinement of Lack's principle. American Naturalist, 100, 687690.

Wolf JB (2000) Gene interactions from maternal effects. Evolution, 54, 1882-1898.

Wright S (1951) The genetical structure of populations. Annual Eugenenic, 15, 323-354.

Wright S (1952) The theoretical variance within and among subdivisions of a population that is in a steady state. Genetics, 37, 312-321.

Wright S (1978) Evolution and Genetics of Populations, Vol. 4 Variability Within and Among Natural Populations. University of Chicago Press, Chicago.

Yang R-C (1998) Estimating hierarchical F-statistics. Evolution, 52, 950-956.

Yang R-C, Yeh FC, Yanchuk AD (1996) A comparison of isozyme and quantitative genetic variation in Pinus contorta ssp. latifolia by $F_{\mathrm{ST}}$. Genetics, $142,1045-1052$.

This work forms the part of Elodie Chapuis' PhD, carried out under the direction of Jérôme Goudet and Sandrine Trouvé. Elodie Chapuis is now a post doctoral fellow, working currently on the evolution of the symbiosis between nematode and bacteria at the Institut des Sciences de L'Evolution de Montpellier (France). Benoit Facon is now a postdoctoral fellow in the same institute. His main interests lie in the ecology of specialization, the behavioural ecology and evolution of reproductive strategies and the evolutionary aspects of biological invasions. Loic Degen was a research assistant on the project, and is currently working for the International Committee of the Red Cross. 